\title{
NOTAS SOBRE DOIS LIVROS DE MACINTYRE ${ }^{1}$
}

\author{
ISABEL RIBEIRO DE OLIVEIRA
}

A conclusão final a que chega MacIntyre em After Virtue, depois de examinar cuidadosamente as razões da crise normativa que, a seu ver, caracteriza a modernidade, é um tanto surpreendente. Ao nos incitar à constituição de comunidades capazes de dar sustentação à vida intelectual e moral, preservando-se assim uma convivência civilizada, deixa na obscuridade a relação que, segundo ele, devemos estabelecer com o "mundo da política". Em uma perspectiva neo-aristotélica, como a por ele adotada, essa é uma relação crucial, posto que, por essa ótica, não é possível pensar a moralidade sem referência à polis. Se entendermos que a comunidade por ele desejada é a própria polis, sua capacidade de resistir ao tempo é diminuta, pois o requisito aristotélico de auto-suficiência não parece estar garantido. E isso porque uma comunidade não tem como constituir-se em algum lugar "vazio" do planeta, situando-se, necessariamente, em território politicamente já ordenado. Posto que sua proposta não estabelece qualquer critério que garanta a civilidade na relação entre a comunidade e a ordem política mais abrangente, talvez o mais apropriado seja interpretá-la como crítica radical da modernidade, antes que enquanto proposta de superação dos problemas por ele, nela, identificados.

De fato, no primeiro capítulo de Justiça de Quem? Qual Racionalidade?, MacIntyre deixa muito claramente postas as razões que o movem em direção a esse insulamento. Referido diretamente ao contexto acadêmico, locus a seu ver particularmente relevante para refletir sobre a justiça, MacIntyre aponta, em primeiro lugar, para a dificuldade que sua

1 Este artigo apresenta resultado parcial da pesquisa "Legado Ibérico e Desafios da Democracia na Contemporaneidade", financiada com recursos do CNPq. 
crítica ao individualismo encontra no campo do pensamento liberal, pois os liberais não se reconhecem no retrato que faz. Admitindo que o modo como trabalha os conceitos de racionalidade prática e sociabilidade natural desagrada aos especialistas em Aristóteles, não espera, da parte deles, a aceitação de suas teses. Os que concordam com sua crítica ao liberalismo tendem a ver no marxismo a alternativa mais interessante; mas, para MacIntyre, o marxismo também é uma tradição de pesquisa já esgotada, esgotamento este demonstrado tanto pela dificuldade em enfrentar os desafios colocados pelo socialismo real quanto por sua debilidade enquanto norteador do governo socialista de sociedades capitalistas. Finalmente, MacIntyre não reconhece o valor da demolição que vem sendo efetivada pelo pensamento pós-moderno. Com todas essas razões, não chega a surpreender o convite a um recolhimento à sua pequena comunidade intelectualmente fértil e moralmente civilizada.

Tendo explicitado já de início os limites de sua perspectiva acerca da justiça, posso agora tratar do que me parece ser sua melhor contribuição para a reflexão acerca dos desafios contemporâneos à democracia.

\section{A ÉTICA FRAGMENTADA}

A metáfora criada por MacIntyre para nos transmitir sua idéia acerca da moralidade contemporânea ajuda a situar seu posicionamento. Sugere que imaginemos uma série de desastres ambientais e a conseqüente responsabilização dos cientistas pela tragédia; laboratórios, instrumentos de pesquisa e livros seriam destruídos e os cientistas, executados. Passado um tempo de "terror ignorante", o desejo de recuperar este saber levaria as pessoas a tentar identificar e compor algo inteligível a partir dos fragmentos restantes, de modo a reconstituir a Química, a Física e demais ciências, tal qual as nomeamos hoje. O desafio seria da mesma ordem do que enfrenta, contemporaneamente, quem busca efetivar um discurso coerente sobre a Ética: deparamo-nos com esquemas conceituais estilhaçados, destituídos do contexto que lhes conferia significado.

Assim, não temos mais uma compreensão efetiva da moralidade, ainda que discursos éticos os mais diversos sigam competindo entre si nos momentos em que precisamos tomar uma decisão sobre o que podemos ou não podemos fazer, ou quando avaliamos a ação governamental. Instaura-se então um debate interminável e aparentemente insolúvel, derivado da heterogeneidade/incomensurabilidade dos conceitos que 
informam as premissas a partir das quais os contendores se posicionam. Em seus discursos, encontramos uma mistura de conceitos modernos, como os advindos da corrente utilitarista ou próprios à linguagem dos direitos, com conceitos tradicionais de virtudes, que se contrapõem e se associam nas formas as mais disparatadas.

Mesmo reconhecendo que cada um dos contendores invoca um critério de justiça, isto é, emite mais do que uma simples preferência, MacIntyre considera que, nos termos em que o debate é realizado, não há possibilidade de se chegar a uma conclusão racional (Mulhall \& Swift, 1992:72). Este paradoxo, sugere MacIntyre, só pode ser resolvido pela História, uma vez que cada discurso tem sua própria fonte em um passado já esquecido, o único capaz de conferir significado claro aos termos utilizados.

Uma determinada linguagem ética, entretanto, a do pluralismo, domina a cena. Sua função é, ao ver de MacIntyre, a de legitimar o caráter inconclusivo desse debate. Pois em nome do pluralismo qualquer versão de moralidade que questione a premissa da irredutibilidade de valores (sugerindo uma pauta menos dispersa e contraditória) é imediatamente rejeitada. No entanto, sustenta, a pretensão de ordenar o campo da ética não deve ser confundida com o intuito de justificar um regime totalitário, e sim reconhecida como seu antídoto. Não é o único, por certo, pois o consenso precário ao qual não raro chegamos, em nossas sociedades pluralistas, com base em argumentações racionais acerca de determinados objetivos coletivos, também o é. Mas MacIntyre não está discutindo com o "campo do pluralismo", e sim com uma de suas vertentes, hoje melhor representada

por Isaiah Berlin. É diante de uma formulação precisa e clara quanto à irredutibilidade dos valores a qualquer consenso efetivo que MacIntyre argumenta que a aceitação deste (pseudo) pluralismo ético nos levaria a aceitar, na prática efetiva da escolha entre propostas distintas da boa vida em sociedade, a tese emotivista. Tendo em vista a riqueza de nosso legado, seria uma pobreza aderir ao emotivismo, que subordina nossa argumentação aos nossos sentimentos, emoções ou preferências subjetivas. Vamos examinar isso mais detidamente.

\section{O EU EMOTIVO E O ARBÍTRIO DO PODER}

Ao analisar a tese emotivista, MacIntyre acentua seu caráter eminentemente reativo a uma moralidade convencional socialmente muito bem instalada. É como se, aos olhos dos que a sustentam, a precariedade 
dos argumentos acionados no debate contemporâneo comprometesse a procedência de qualquer tipo de argumentação racional. A invocação de critérios objetivos (referidos a alguma representação do bem ou da utilidade) para decidir ou avaliar escolhas seria interpretada como o acionamento de um mecanismo de 'racionalização' da vontade de poder. Se o que importa para os contendores é a expressão de seus sentimentos e atitudes, de modo a persuadir os outros de que tais emoções são as apropriadas para informar o julgamento, o uso de um 'argumento racional' nada mais seria que um recurso estratégico visando a obtenção desse fim. Nessa perspectiva, o espaço público não se configura, propriamente falando, como espaço propício à interlocução, e sim como lugar de embate entre vontades emocionadas, onde cada qual se apresenta com "seu próprio conjunto de atitudes e preferências entendendo o mundo apenas como uma arena para... (sua) satisfação" (1984:25). Em outras palavras, se o comportamento humano é interpretado nesses termos pela corrente emotivista, a leitura das relações sociais que aí se faz estará presumindo que o 'outro' é concebido como um objeto, entre os demais, destinado a ser manipulado. Interpretar uma disputa dessa forma eqüivale a desconsiderar a condição propriamente humana dos interlocutores enquanto capazes de determinar de forma independente o que racionalmente julgam ser certo. ${ }^{2}$

Isto é considerado por MacIntyre um problema sério porque nos impede de distinguir interações sociais manipulativas das interações não manipulativas, distinção que usamos com freqüência, em nosso discurso ético, para separar as emoções que o caso em pauta suscita em nós dos critérios que serenamente usamos para aprovar ou desaprovar seu encaminhamento. Um segundo aspecto, desse mesmo problema, é o fato de que todas as preferências são consideradas igualmente válidas ou igualmente arbitrárias. O que confere valor a cada uma delas não é, propriamente dizendo, o que é desejado, e sim o fato de que a escolha por esse ou aquele valor se faz livremente. Desde que assim feita, qualquer escolha, a qualquer momento, por qualquer meta, deverá ser aceita. Ao ver de MacIntyre, esse elogio desmesurado da liberdade compromete o próprio sentido da vida, que não tem mais como ser coerente, íntegra ou, simplesmente, inteligível.

2 Vale notar, nesse elogio da interlocução, como acuradamente aponta Fowler (1991:93), a ressonância do pensamento de Stuart Mill. 
Sabe ele muito bem que não dispomos de um lugar 'neutro' para fazer os ajustes entre os diversos argumentos cuja racionalidade é tributária de distintas tradições. Mesmo assim, nossa história nos mostra a produtividade dos confrontos que viabilizam momentos preciosos de síntese. Reconhecendo que vivemos em uma cultura emotivista, onde temos dificuldade em mostrar que estamos buscando uma comunicação racional antes que seduzir o outro, MacIntyre insiste naquele intuito, identificando o luto mal feito da perda das ilusões iluministas como principal barragem à sua efetivação. Foi por supor que a ética pudesse fundar-se em verdades universais que o pensamento posterior, constatando a impropriedade da suposição, refuta qualquer proposta de diálogo entre discursos éticos, justificando-se assim o relativismo ou pluralismo de valores.

Mas não há porque postular que a persuasão só possa efetivar-se num contexto emancipado da 'contingência e da particularidade' da tradição. Desde que preservado o respeito para com o que é considerado evidente, em acordo com as regras da lógica, a racionalidade necessária à formulação de julgamentos morais objetivos está garantida. Tais julgamentos não precisam ser válidos em qualquer circunstância. Eles são pertinentes desde que guardem um teor de objetividade que permita diferenciálos dos julgamentos derivados, estritamente, de nossas emoções.

É o desenvolvimento dessa perspectiva que será examinado, a seguir.

\section{PRÁTICA, NARRATIVA E TRADIÇÃO}

A objetividade postulada por MacIntyre deriva da associação que reconhece entre moralidade e estrutura social, no sentido de que as regras que asseguram a cada pessoa seu lugar na sociedade e lhe conferem identidade também prescrevem o que ela deve (suas obrigações) e o que lhe é devido, e como ela (e os outros) será tratada e vista caso fruste essas expectativas (1984:123). Tais regras expressam o acordo quanto aos fins da política e, portanto, a existência de um entendimento comum, um consenso quanto ao bem a ser buscado pela coletividade. E são elas que estabelecem os limites para o exercício correto (virtuoso) da liberdade individual. MacIntyre enfatiza, portanto, a estreita conexão da moralidade (ethikos ou moralis) com a institucionalidade própria a cada sociedade, ponto relevante para basear sua crítica tanto à pretensão moderna de construir uma ética universal (1984:39) quanto ao ceticismo relativista. 
Se tal conexão não elimina o espaço de liberdade individual, sua conceituação difere radicalmente daquela própria ao liberalismo. Nessa tradição, individualiza-se cada ação humana, separa-se o indivíduo dos papéis que ele desempenha, denotando a liberdade o modo pelo qual cada pessoa ordena suas preferências com vistas à realização de seus desejos. ${ }^{3}$ Para produzir uma concepção alternativa desse elo, MacIntyre apóia-se na tradição aristotélica. Dela, retira a idéia de que, como qualquer espécie, a espécie humana tem sua natureza própria, que lhe confere o fim a que se destina, seu telos, a ser realizado ao longo de sua existência. A eudaimonia, que pode ser traduzida, ainda que de forma um tanto elusiva, por felicidade, é um estado em que a pessoa sente-se bem e faz o bem. Se são as virtudes que permitem alcançar este estado, elas não devem ser tomadas como um meio para alcançar o fim, já que

(...) o que constitui o bem para o homem é uma vida humana completa vivida no seu melhor, e o exercício das virtudes é uma parte necessária e central de tal vida, não apenas um exercício preparatório para garanti-la (1984:149).

Como a realização desta vida boa só é possível na polis, porque só neste espaço podem os cidadãos partilhar bens comuns, constituindo-se os elos de amizade, a liberdade não deve situar-se na esfera íntima do indivíduo, referindo-se, alternativamente, a decisões concernentes ao ordenamento da própria sociedade.

Essa recuperação do pensamento aristotélico, na contemporaneidade, enfrenta duas dificuldades cruciais. A primeira delas é a de que o telos estaria referido a uma essência humana compreendida nos termos da biologia metafísica de Aristóteles. A segunda é a centralidade conferida aos elos de amizade, algo possível em uma polis formatada como cidadeEstado, cujo tamanho permite o conhecimento mútuo entre os cidadãos. É no intuito de superá-las que MacIntyre desenvolve os conceitos de prática, narrativa e tradição.

Qualquer atividade humana cooperativa, socialmente estabelecida, constitui uma prática, que contém 'bens internos', intrínsecos a ela. Tais bens, indivisíveis, não podem ser individualmente apropriados; de

${ }^{3}$ Para uma análise cuidadosa do conceito de liberdade no campo do liberalismo e republicanismo contemporâneos, cf. Melo (2002). 
resto, não há porque tratá-los atomisticamente. Para obtê-los é necessária a obediência às regras próprias à prática, que estão submetidas a padrões de excelência. Jogar xadrez, fazer ciência, cuidar da casa, são exemplos de práticas. Uma prática envolve, portanto, padrão de excelência, obediência a regras e obtenção dos bens.

Cabe notar que se a prática é uma atividade que requer submissão à autoridade do padrão de excelência vigente, tal submissão não impede sua mudança, como fica claro ao se constatar que as práticas têm uma história. No entanto, não se pode ser iniciado numa prática e, muito menos, criticá-la, sem aceitar a autoridade dos melhores padrões já realizados. Para ser admitido a uma prática social, é necessário entrar em relação não apenas com os que a praticam, mas também com sua tradição. É esta que permite distinguir a prática efetiva do contexto institucional onde se realiza, algo essencial, tendo em vista o poder corruptor das instituições (1984:194).

É nessa conceituação da atividade humana que MacIntyre introduz a virtude como qualidade adquirível cuja posse e exercício tendem a possibilitar a obtenção dos bens internos às práticas. O exercício das virtudes implica uma escolha, que se apresenta na forma de uma decisão racional de cultivar e encorajar, reduzir ou inibir emoções e desejos. Seu primeiro efeito é o de treinar o indivíduo para o autocontrole, educando os sentimentos e requerendo o uso da inteligência. Nestes termos, MacIntyre acredita ter contornado o problema da determinação biológica em sua teleologia, conferindo relevância à institucionalização do contexto onde o indivíduo se inscreve e busca sua auto-realização. Tal reformulação do conceito de indivíduo permite fazer o luto dessa figura abstrata de um indivíduo racional e volitivo, que independentemente dos demais estabelece seus próprios fins, substituindo-a por outra onde o indivíduo é sempre alguém que desempenha um papel ou exercita uma prática. $\mathrm{O}$ contexto fornece também os critérios a serem acionados para julgar o desempenho individual e, nesse sentido, o julgamento de valor passa a ser compreendido como um julgamento de fato, isento da arbitrariedade que lhe é atribuída pelo enfoque relativista.

Se o argumento exposto até aqui parece plausível para estabelecer, quando referido a uma prática determinada, a objetividade do julgamento, ele é insuficiente para dar conta da avaliação de práticas que competem ou conflitam entre si. A dificuldade é identificada, por MacIntyre, como sendo de natureza sociológica. A seu ver, esse problema só se coloca na modernidade, onde a vida está fragmentada numa variedade de 
segmentos, cada qual com suas normas e modos de comportamento. Separando o trabalho do lazer, a vida privada da pública, e mais, a infância e a velhice sendo compreendidas como fases estanques, a modernidade desfigura a vida humana. Com isso, fica em questão a própria existência do Eu.

O conceito de narrativa será então acionado para dar conta da unidade do self, de modo a especificar o bem que lhe é próprio (1984:203). A unidade almejada só pode ser realizada se for possível responder pelas intenções do eu, explicando seus atos ao longo da vida. Para tanto é necessário ordenar tais intenções de modo a identificar os elos causais e o efeito temporal, relativamente ao papel que desempenham em sua história. Mas a narrativa deverá ainda dar conta do contexto onde transcorre a vida, contexto esse que também se altera ao longo do tempo, conferindo-lhe assim inteligibilidade. Ora, essa inteligibilidade terá sempre um caráter precário, pois em boa parte é conferida pelo próprio ator que atua sempre num contexto que o constrange. No entanto, é melhor suportar a precariedade do que abrir mão dela e ver a própria vida reduzida a um conjunto de ações discretas, perspectiva existencialista que não lhe apraz.

A narrativa tem a função de integrar papéis ou práticas, ao mesmo tempo em que especifica o significado a ser conferido à idéia central de telos. Ela provê o arcabouço dentro do qual fazemos nossas escolhas racionais frente às demandas conflituosas das práticas das quais participamos (Mulhall \& Swift, 1992:88). MacIntyre mostra como é natural, em nossa cultura, falarmos de nós mesmos através de uma narrativa. Ao contar nossa história, localizamo-nos no tempo e no espaço social, isso é, descrevemos o contexto onde se deu nossa ação, onde fizemos escolhas informados por nossas intenções e movidos pelo que acreditamos ser importante. Nessa narrativa está claramente destacado o fato de que o ator, o sujeito que age, que exercita o poder, é possivelmente também o autor de seu gesto. Mas esta autoria é, mais propriamente falando, uma co-autoria.

O primeiro aspecto a ser ressaltado nessa idéia de narrativa é então o da autoria num contexto onde a liberdade do gesto esta constrangida pela ação do outro. O segundo aspecto, daí decorrente, é o da incerteza. Se nossa história individual e coletiva adquire inteligibilidade, essa inteligibilidade está sempre sujeita a confrontos com situações imprevistas, e cada uma delas, por sua vez, define uma gama de desdobramentos possíveis. O terceiro aspecto é o de que essa narrativa que vamos construindo não emerge do nada, fazendo parte de um relato que nos antecede, no sentido de que entramos na sociedade com um 
personagem para nós já preparado, papéis que teremos que aprender a desempenhar para compreender o que os outros esperam de nós e como podemos responder adequadamente a eles. Essa socialização não está nos transmitindo, apenas, as normas sociais, mas também definindo quem devemos ser. A ação humana, portanto, não é um fato isolado, mas um episódio de uma história possível.

O que um conceito de indivíduo, enquanto construído pela narrativa, requer é, de um lado, a admissão de que eu sou o sujeito de minha história, e que esta história tem um significado peculiar; de outro, a de que sou também o sujeito da história dos outros. Ser o sujeito da minha história eqüivale a poder dar conta das ações e experiências que compõem essa vida narrável. É estar aberto para responder a perguntas de porque fiz isto ou aquilo neste ou naquele ponto da minha vida. Mas esse conceito introduz um outro aspecto relacional igualmente relevante, que é o de que ele nos instiga a saber porque o outro fez o que fez, pois que sou parte de sua história. A narrativa de uma historia individual é, portanto, parte de um conjunto de narrativas interconectadas. Assim, qualquer tentativa de elucidar a noção de identidade pessoal independente e isoladamente das noções de narrativa, inteligibilidade e responsabilidade (accountability), está destinada ao fracasso.

Feitas essas considerações, MacIntyre pode então sustentar que o bem que buscamos é o de uma vida cujo relato dê conta de nossas ações, conferindo significado ao personagem que conseguimos ser. Se o self só se realiza em sociedade, se sua identidade só pode ser construída no âmbito da comunidade onde vive, é necessário aceitar os limites dessa comunidade, para atuar livremente. $\mathrm{O}$ sucesso nesse empreendimento requer a incorporação da tradição, do passado ainda presente na condição em que se vive, que carregamos conosco e que constrange nossa capacidade de refletir. Constrange, mas nutre também, pois é a familiaridade com a tradição que abre o campo das possibilidades que não se tornaram realidade, mas que podem ser projetadas no futuro.

Posto isso, é possível dizer que a unidade da vida humana consiste em uma narrativa incorporada em uma única vida, e que o bem desta vida é obtido pela resposta de como posso viver esta unidade e levá-la à sua completude. Perguntar o que é bom para o homem é o mesmo que responder a estas questões em comum, que é o que confere unidade à vida moral. Essa busca de unidade implica um telos que vai sendo desenhado pelas respostas dadas às dificuldades que vão aparecendo. Mas não se trata de uma busca individual, uma vez que 
nossas identidades são socialmente constituídas. É aqui que entra seu conceito de tradição, isso é, de um passado que mostrou possibilidades futuras que não chegaram a se efetivar.

O argumento efetivo que MacIntyre está desenvolvendo é portanto, uma inflexão no tratamento usualmente dado ao conflito entre valores, na medida em que não é no campo da razão pura que ele imagina encontrar sua solução. Não há porque buscar uma meta-virtude, cabendo, alternativamente, eleger como lugar apropriado para o encaminhamento desse conflito a prática social empreendida por um self bem situado.

\section{CONCLUSÃO}

Isaiah Berlin, tão próximo do raciocínio weberiano, considera que os bens que desejamos ao longo de nossa vida são de tal forma heterogêneos que seria quixotesco buscar sua reconciliação em uma única pauta valorativa. Ao sustentar que as virtudes não podem ser tratadas separadamente da institucionalidade da vida social, MacIntyre pode colocar em questão essa premissa central do pluralismo. A meu ver, o ponto mais importante dessa crítica é o que permite conferir um outro significado à prática política, pouco valorizada no âmbito do pluralismo, pois a institucionalidade política, cujo telos é a manutenção das demais instituições sociais num arranjo relativamente coeso e autônomo, passa a ocupar um lugar de centralidade em sua teoria de justiça.

É essa a perspectiva que permite a MacIntyre, no capítulo $17 \mathrm{de}$ Justiça de Quem? Qual Racionalidade?, questionar o valor da tolerância, exaltado pelo, e de resto, intrínseco ao pluralismo. A idéia de que crenças, comportamentos e modos de vida individuais e coletivos, pautados por valores os mais díspares, devam ser tolerados desde que não comprometam o funcionamento da ordem política em curso está alicerçada em duas premissas. A primeira delas é de que indivíduos e grupos tem direito de exercitar sua liberdade, construindo os mundos onde querem viver. Tal liberdade só pode ser legitimamente limitada quando seu exercício infringe a cláusula da universalidade, isto é, do igual direito de todos de exercerem a mesma liberdade. A segunda premissa é a de que cabe ao Estado proteger a ordem política assim constituída, expressando desse modo o consenso existente na sociedade acerca de sua devida função. As esferas pública e privada estariam, portanto, claramente delimitadas, não tendo a primeira outra razão de ser do que a preservação da segunda. 
O questionamento de MacIntyre orienta-se, inicialmente, para a dificuldade, em uma ordem assim articulada, de estabelecer o princípio de obrigação política. Que razões levariam os indivíduos a abdicar de suas preferências, aceitando a ordenação específica que regula o espaço de sua liberdade? O que está em pauta aqui não é a possível aceitação por todos da imprescindibilidade de limites ao exercício da vontade, mas a arbitrariedade intrínseca à apresentação do campo de escolhas onde ela se efetiva. No final deste livro deixa clara sua objeção:

Em qualquer sociedade em que o governo não expresse ou represente a comunidade moral dos cidadãos, mas, alternativamente, um conjunto de arranjos institucionais para impor uma unidade burocrática em uma sociedade que carece de um consenso moral genuíno, a natureza da obrigação política tornase sistematicamente obscura (1988:254).

Quando no centro da cena está o conceito de preferência, isto é, o que quer que seja que os indivíduos (figura de razão e vontade, criada pelo pensamento liberal) manifestarem, o princípio ético acionado é o da igualdade formal. Pela perspectiva aberta por MacIntyre, a política passa, alternativamente, a ser vista como uma prática que contém bens internos. Mas não é apenas na perspectiva liberal da política que este reconhecimento mostra-se inviável. A transformação social devida à industrialização impede a maioria das pessoas de reconhecer a existência de bens internos às suas práticas. Pois na medida em que o trabalho passa a estar a serviço do capital impessoal, essa atividade separa-se de tudo que não esteja a serviço da manutenção da vida fisiológica, fixando-se, portanto, em sua própria reprodução e/ou na aquisitividade por ele possibilitada. "Pleonexia", um vício no esquema aristotélico, é agora a força motora da modernidade. Artes, ciências e jogos passam a ser praticadas apenas por minorias. A maioria apenas consome a estética.

$\mathrm{Na}$ tradição aristotélica tal problema não se coloca porque o que a educação virtuosa ensina é que meu bem, como ser humano, é o mesmo para outros com os quais estou ligado em uma comunidade. As virtudes individuais, aqui, são as que levam o indivíduo a tomar o bem público, anterior e caracterizável independentemente da soma dos interesses e desejos individuais, como referência para seu comportamento. Não há possibilidade de buscar o meu bem e antagonizar um outro que também procura seu bem, porque o bem não é meu nem dele, o bem não é uma propriedade 
privada. Aamizade, a forma fundamental de relacionamento humano envolve, precisamente, partilhar bens. Nesta perspectiva, o egoísta é alguém que cometeu um erro fundamental.

ISABELRIBEIRO DE OLIVEIRA é professora titular do Departamento de Ciência Política da Universidade Federal do Rio de Janeiro e pesquisadora do CNPq.

\section{REFERÊNCIAS BIBLIOGRÁFICAS}

FOWLER, R. B. (1991). The Dance with Community - The Contemporary Debate in American Political Thought, Kansas: Univ. Press of Kansas.

MACINTYRE, A. (1984). After Virtue. 2. ed. Notre Dame: University of Notre Dame Press. (1988). Justiça de Quem? Qual racionalidade? : Petrópolis: Ed. Loyola,

MELO, M. A. (2002). "Republicanismo, liberalismo e racionalidade" In Lua Nova, n.55-56, São Paulo

MULHALL, S. \& SWIFT, A. (1992). Liberals and Communitarians. Cambridge: Blackwell. 


\section{RESUMOS/ABSTRACTS}

\section{NOTAS SOBRE DOIS LIVROS DE MACINTYRE}

ISABEL RIBEIRO DE OLIVEIRA

Os conceitos centrais da teoria da justiça desenvolvida por Alasdair MacIntyre - prática, narrativa e tradição - ocupam o núcleo da análise feita acerca de dois de seus livros: Depois da Virtude e Justiça de Quem? Qual racionalidade?. O artigo considera a relação, em MacIntyre, entre ética e história, virtude e relativismo, bem como apresenta seu conceito do $\mathrm{Eu}$, como corretivos à anomia contemporânea.

Palavras chaves: Teoria da Justiça; Concepções do Eu; Ética; A. MacIntyre.

\section{NOTES ON TWO BOOKS BY MACINTYRE}

The central concepts of MacIntyre's approach to justice practice, narrative and tradition - constitute the main trust of the analysis of two of his books: After Virtue and Whose justice? Which rationality?. The article elaborates on the relationship of ethics to history, of virtues to relativism as well as his conception of the self as correctives to the pervasive anomie in contemporary societies.

Key words: Theories of Justice; Conceptions of the Self; Ethics; A. MacIntyre. 